\title{
The biological effects of coarse and fine particulate matter
}

\section{K Donaldson}

\section{A new chapter in the long history of the toxicology of air pollution particles}

D ecember 2002 saw a 50th anniversary that marks one of the great milestones in environmental medicine. On 4 December 1952 London was enveloped in a thick fog. An anticyclone then caused a temperature inversion that trapped air pollution from millions of domestic coal fires and the fog grew daily into a choking smog that settled over London. Over the days of 4-9 December visibility was reduced to a few yards at midday and pedestrians collected a layer of oily soot on their clothes and skin. About 4000 deaths were attributed to the smog but there is now evidence that the number of deaths may have reached 12000 . As a direct consequence of "The Great London Smog" the government began to put together legislation, culminating in the Clean Air Acts, which introduced smokeless zones. From this beginning we can track the successful improvement in UK air pollution that has culminated in the relatively clean and clear skies that most of us enjoy today.

\section{"In many cities in the world air pollution is still very high"}

However, the effects of air pollution can still be detected. There are many cities in the world where air pollution is still very high, such as Mexico City, Los Angeles, and Beijing. Improved computer programs and the ability to study enormous populations also allows very small effects in populations to be detected. When these epidemiological techniques are applied, there are still detectable adverse effects of increases in air pollution, even in the UK's relatively unpolluted climate. Of the components of the air pollution cocktail, the particles (particulate matter, PM), seem to be the most harmful. The average levels of PM in UK cities, measured by DEFRA's Automated Urban Network of analytical sites as the mass of particles per unit volume of air, is around $20 \mu \mathrm{g} / \mathrm{m}^{3}$; they were $400 \mu \mathrm{g} / \mathrm{m}^{3}$ during the Great London smog. When the PM levels increase, asthma attacks increase as do exacerbations of smokers' lung disease-chronic obstructive pulmonary disease (COPD) - as well as deaths from COPD; more surprisingly, deaths from cardiovascular causes also increase.

In addition to the acute effects of rises in $\mathrm{PM}_{10}$, usually detected in the hours and days following the increase, there is evidence of chronic effects of $\mathrm{PM}_{10}$. In the famous six cities study, ${ }^{1}$ over 8000 deaths were studied and compared to the levels of air pollution in which the people lived. Adjusted mortality rate ratio, corrected for smoking, for the most polluted of the cities compared with the least polluted, showed a quarter more deaths from lung cancer and cardiopulmonary disease. The link to lung cancer, of living in an area with high levels of air pollution particles, was further confirmed recently in a study using data from the American Cancer Society. In this study, living in an area with a $10 \mu \mathrm{g} / \mathrm{m}^{3}$ increase in fine particulate air pollution was associated with an $8 \%$ increased risk of lung cancer mortality.

These effects of $\mathrm{PM}_{10}$, found by epidemiologists in the modern era studying large populations, were initially greeted with scepticism, because of the very low levels of particles involved-that is, a few tens of $\mu \mathrm{g} / \mathrm{m}^{3}$. To put this into perspective, the HSE standard for nuisance dusts in the workplace-that is, dusts that are not known to have any very toxic components-is $4000 \mu \mathrm{g} / \mathrm{m}^{3}$. Much of the mass of PM is ammonium salts and wind blown dust that has no toxicity at the tiny levels present; particle toxicologists have therefore had some difficulty in believing that there was a plausible mechanism for these reported effects, especially the cardiovascular ones.

However, in the past 10 years there has been an exceptional amount of research activity to address this puzzle and, on balance, a paradigm that provides a degree of plausibility has evolved, at least among toxicologists. This paradigm has several elements:

(1) The combustion derived components of $\mathrm{PM}_{10}$ which are ultrafine
$(<100 \mathrm{~nm})$ in size and can be metal and PAH-rich are most likely to be the harmful component.

(2) Oxidative stress, arising from these particles and their associated metals and organics, elicits inflammation which drives the local and cardiovascular effects.

(3) The adverse effects are seen in susceptible groups only, whose preexisting lung or heart disease makes them more likely to succumb to the very low extra inflammation that they get from the air pollution particles.

This paradigm is still very much a hypothesis that is undergoing testing.

In the case of the link between PM and cancer, the oxidative stress paradigm is less secure. The paper in this issue by Shi et al from the Particle Research group in the IUF at the University of Dusseldorf shows that, in vitro, PM has the ability to cause specific DNA adducts that form through oxidative stress pathways. ${ }^{3}$ The pathway from DNA adducts to accumulations of mutations, culminating in transformation to a cancer cell, is already well documented. Coarse and fine PM samples were collected in Dusseldorf and tested for their ability to generate hydroxyl radicals, using a spintrap in the highly specific electron paramagnetic resonance technique. Hydroxyl radicals are the most harmful free radical formed in tissue under oxidative stress conditions and are capable of combining with the guanine in DNA to form a specific adduct 8-hydroxy2 -deoxyguanosine $(8-\mathrm{OHdG})$. All of the PM samples were able to generate hydroxyl radical and contained transition metals such as $\mathrm{Cu}, \mathrm{V}$, and Fe, which can chemically react with lung molecules to produce the hydroxyl radical. There was, however, no direct relation between the levels of single transition metals in the samples and their ability to cause the DNA adducts, suggesting that factors other than metals might be involved in generating hydroxyl radical. Organic molecules such as PAHs and quinones, both present on combustion derived $\mathrm{PM}_{10}$, have been implicated in redox cycling and oxidative stress and could be the culprits. When the PM samples were mixed with naked DNA, the $8-\mathrm{OHdG}$ adduct was formed; these adducts were also seen in lung epithelial cells incubated with particles, a more realistic exposure than direct incubation of PM with DNA. In contrast to the prevailing hypothesis regarding the role of small combustion derived particles, this study showed a greater effect overall with the coarse fraction; however, small particles aggregate and filter derived samples are not necessarily recovered in the same size fractions as they were present in the air. 
This report makes a clear link between PM mediated oxidative stress and formation of a DNA adduct, an endpoint relevant to cancer. Apart from making a link to lung cancer, the authors suggest that their method of assessing oxidative stress should be investigated as an alternative metric to mass, particle composition, and particle number in PM regulation. Shi and colleagues' paper raises, like all good science, more questions than it answers, but it opens up a new chapter in the long history of the toxicology of air pollution particles, which is especially apposite on the 50th anniversary of the Great London Smog.

Occup Environ Med 2003;60:313-314

Author's affiliation

K Donaldson, University of Edinburgh Medical School, UK

Correspondence to: Prof. K Donaldson, ELEGI Colt Laboaratory, Wilkie Building, University of Edinburgh Medical School, Teviot Place,
Edinburgh EH8 9AG, UK; ken.donaldson@ed.ac.uk

\section{REFERENCES}

1 Dockery DW, Pope CA, Xu XP, et al. An association between air-pollution and mortality in 6 United States cities. N Engl J Med 1993;329:1753-9.

2 Pope CA III, Burnett RT, Thun M, et al. Lung cancer, cardiopulmonary mortality, and ong-term exposure to fine particulate air

pollution. JAMA 2002;287: 1 132-41.

3 Shi T, Knaapen AM, Begerow J, et al. Temporal variation of hydroxyl radical
generation and 8-hydroxy-2'-deoxyguanosine generation and 8-hydroxy-2'-deoxyguanosing matter. Occup Environ Med 2003;60:315-21.

\section{Clinical Evidence-Call for contributors}

Clinical Evidence is a regularly updated evidence based journal available worldwide both as a paper version and on the internet. Clinical Evidence needs to recruit a number of new contributors. Contributors are health care professionals or epidemiologists with experience in evidence based medicine and the ability to write in a concise and structured way.

Currently, we are interested in finding contributors with an interest in the following clinical areas:

Altitude sickness; Autism; Basal cell carcinoma; Breast feeding; Carbon monoxide poisoning; Cervical cancer; Cystic fibrosis; Ectopic pregnancy; Grief/bereavement; Halitosis; Hodgkins disease; Infectious mononucleosis (glandular fever); Kidney stones; Malignant melanoma (metastatic); Mesothelioma; Myeloma; Ovarian cyst; Pancreatitis (acute); Pancreatitis (chronic); Polymyalgia rheumatica; Post-partum haemorrhage; Pulmonary embolism; Recurrent miscarriage; Repetitive strain injury; Scoliosis; Seasonal affective disorder; Squint; Systemic lupus erythematosus; Testicular cancer; Varicocele; Viral meningitis; Vitiligo

However, we are always looking for others, so do not let this list discourage you.

Being a contributor involves:

- Appraising the results of literature searches (performed by our Information Specialists) to identify high quality evidence for inclusion in the journal.

- Writing to a highly structured template (about 2000-3000 words), using evidence from selected studies, within 6-8 weeks of receiving the literature search results.

- Working with Clinical Evidence Editors to ensure that the text meets rigorous epidemiological and style standards.

- Updating the text every eight months to incorporate new evidence.

- Expanding the topic to include new questions once every 12-18 months.

If you would like to become a contributor for Clinical Evidence or require more information about what this involves please send your contact details and a copy of your CV, clearly stating the clinical area you are interested in, to Claire Folkes (cfolkes@bmigroup.com).

\section{Call for peer reviewers}

Clinical Evidence also needs to recruit a number of new peer reviewers specifically with an interest in the clinical areas stated above, and also others related to general practice. Peer reviewers are health care professionals or epidemiologists with experience in evidence based medicine. As a peer reviewer you would be asked for your views on the clinical relevance, validity, and accessibility of specific topics within the journal, and their usefulness to the intended audience (international generalists and health care professionals, possibly with limited statistical knowledge). Topics are usually 2000-3000 words in length and we would ask you to review between 2-5 topics per year. The peer review process takes place throughout the year, and our turnaround time for each review is ideally 10-14 days.

If you are interested in becoming a peer reviewer for Clinical Evidence, please complete the peer review questionnaire at www.clinicalevidence.com or contact Claire Folkes (cfolkes@bmigroup.com). 